\title{
Public Finance Policy Strategies to Increase Access to Preconception Care
}

\author{
Kay A. Johnson
}

Published online: 27 June 2006

(C) Springer Science+Business Media, Inc. 2006

\begin{abstract}
Policy and finance barriers reduce access to preconception care and, reportedly, limit professional practice changes that would improve the availability of needed services. Millions of women of childbearing age (15-44) lack adequate health coverage (i.e., uninsured or underinsured), and others live in medically underserved areas. Service delivery fragmentation and lack of professional guidelines are additional barriers. This paper reviews barriers and opportunities for financing preconception care, based on a review and analysis of state and federal policies. We describe states' experiences with and opportunities to improve health coverage, through public programs such as Medicaid, Medicaid waivers, and the State Children's Health Insurance Program (SCHIP). The potential role of Title V and of community health centers in providing primary and preventive care to women also is discussed. In these and other public health and health coverage programs, opportunities exist to finance preconception care for low-income women. Three major policy directions are discussed. To increase access to preconception care among women of childbearing age, the federal and state governments have opportunities to: (1) improve health care coverage, (2) increase the supply of publicly subsidized health clinics, and (3) direct delivery of preconception
\end{abstract}

\author{
K. A. Johnson \\ Dartmouth Medical School, \\ Hanover, $\mathrm{NH}$, \\ USA
}

K. A. Johnson $(\bowtie)$

Department of Pediatrics/CHAD,

One Medical Center Drive, Lebanan, NH 63756 screening and interventions in the context of public health programs.

Keywords Finance $\cdot$ Policy $\cdot$ Maternal health $\cdot$ Infant health · Preconception · Medicaid · Title V · Family planning

\section{Introduction}

The overarching goal of preconception care is to provide health promotion, screening, and interventions for the more than 62 million women of childbearing age [1] to reduce risk factors that might affect future pregnancies [2-4]. As elsewhere in this supplement, preconception care is defined as a set of interventions that aim to identify and modify biomedical, behavioral, and social risks to a woman's health or pregnancy outcome through prevention and management, emphasizing those factors which must be acted on before conception or early in pregnancy to have maximal impact. It includes care before a first pregnancy or between pregnancies (commonly known as interconception or internatal care) [5], and care that would typically be delivered in primary care settings [4].

Health professional leaders and professional organizations' guidelines have called for improvements in preconception care for more than 20 years [4, 6-9]. and several reviews of the literature have assessed the evidence for specific interventions and documented their effectiveness [10, 11]. Without changes in financing, however, it appears unlikely that the nation will improve its preconception health and, thereby, improve the health of women, their children, and their families. Since federal and state policies are important drivers of health care financing, this paper provides suggestions on how policymakers can improve financing for preconception care [12]. 
Although many observers have suggested that providers would deliver more preconception care if they could bill payers for the service [13], a closer look at the situation suggests that more complex changes in women's health care financing may be necessary to support widespread use of preconception care. Affordability of care is a major concern for many women [14]. Many women lack basic health coverage, particularly non-pregnant, low-income women who do not meet of Medicaid's low income eligibility levels [15]. Securing private insurance coverage for additional preventive services may require more and better evidence about the effectiveness of interventions [4]. Other barriers to financing are more mechanical. Financing is required for an ongoing care process over a period of years and across the lifespan, not a single visit. Billing mechanisms and codes need refinement; in addition, cost-benefit analyses, and ongoing alignment with newly emerging approaches to care will also be required [16].

\section{Improving health coverage for women of childbearing age}

Financial barriers to health care access are widespread in the United States, with many low-income individuals having no or inadequate health coverage. The Kaiser Family Foundation's, Women's Health Survey [17] does not focus on preconception care, but some of its results are relevant to understanding barriers to women's health care. Among women of childbearing age (18 to 44 years) 30 percent reported that they delayed or went without care because of cost. Moreover, $21 \%$ of women of all non-elderly women (18 to 64 years) in the survey reported that they did not fill a prescription for medication because of cost, including $40 \%$ of uninsured women [17].

\section{Uninsured women}

Millions of Americans live without health coverage. Nearly 17 million American women are uninsured [17]. One-third of low income women (with income less than 200 percent of the federal poverty level), half of women with disabilities, and 18 percent of all non-elderly women were uninsured in 2003 [18]. Younger women were more likely than older women to be uninsured. Hispanic, Asian, and Black women were more likely than non-Hispanic white women to be uninsured, reflecting their income and employment status patterns (i.e., more likely to have incomes below 200 percent of poverty and less likely to be employed in jobs that offer health insurance) [17]. Moreover, recent data indicate that women are more likely to lose coverage than men. Between 2002 and 2003, nearly 900,000 women ages 18 to 64 became uninsured, compared to 600,000 men (53 and 47 percent, re-

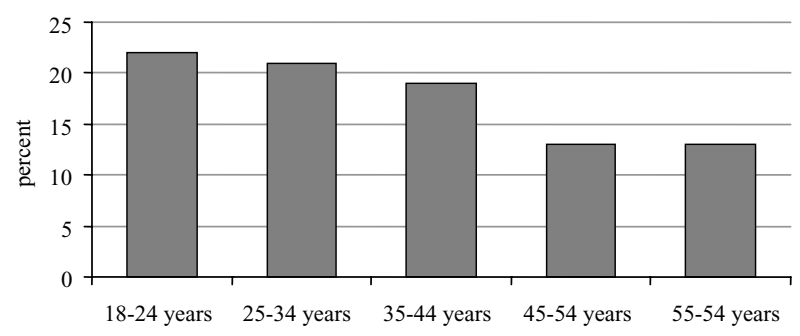

Fig. 1 Percent of Non-Elderly U.S. Women who are Unisured, By Age, 2004

spectively). Such losses are attributed primarily to welfare reform policies and employer-based coverage trends [19].

Data for 2002-2003 reveal that the percentage of women ages 18-64 who were uninsured varies substantially, ranging from 30 percent in Texas to 8 percent in Minnesota. The proportion of uninsured low-income adult women shows similar variation, ranging from more than 50 percent in Texas to less than 25 percent in Massachusetts, Minnesota, Tennessee, and Wisconsin. Although to some extent these differences reflect Medicaid eligibility policy, the state-to-state variations also reflect employment patterns. For example, Minnesota had the highest percentage of adult women with private coverage and a fairly low proportion of women covered by Medicaid (83 percent and 8 percent, respectively). In contrast in Tennessee (under policies in effect at that time), 17 percent of adult women were Medicaid beneficiaries and only 70 percent had private coverage [20].

Women who are young, single, working part-time, or unemployed are most likely to uninsured. These factors are reflected in an age gradient, the percent of uninsured women ranging from 22 percent among 18 to 24 year olds, 21 percent among 25 to 34 year olds, 19 percent among 35 to 44 year olds, and 13 percent among 45 to 54 year olds (Fig. 1). Moreover, women ages 25-44 accounted for more than half (53 percent) of all uninsured women under age 65 [17].

\section{Medicaid as a source of coverage for women's health and PCC}

Medicaid is effective in improving access to health care for low income women. Medicaid coverage affords women access to essential preventive, primary, and reproductive health care services, thereby allowing them to reduce unintended pregnancy, choose the number and spacing of their pregnancies and, when desired, to plan a healthy birth [21]. Medicaid plays a particularly important role in financing ambulatory care for women of childbearing age [22]. While Medicaid coverage and enrollment for women declined during the mid1990s as a result of changes in health and welfare policies, Medicaid demonstration waiver projects are now being used 
by some states expand to access to health care for women of childbearing age.

Under current Federal and State policies, Medicaid is the primary mechanism for extending health coverage for low-income, uninsured women. In 2003, 12 percent of all women of childbearing age (15-44 years) and 37 percent of poor women in that age group relied on Medicaid for health care coverage. Because nearly two-thirds (63 percent) of the women covered by Medicaid are of childbearing age (19-44 years), the program's performance is related to preconception care access and to the outcomes of pregnancy [17].

Federal and state policies together define eligibility rules for Medicaid. Data from the Centers for Medicare and Medicaid Services (CMS) for female beneficiaries in the year 2000 indicate that 26 percent became eligible because they were pregnant and had low income, while 42 percent had welfare/poverty-linked eligibility [23]. Federal law requires that states extend Medicaid eligibility to pregnant women with income below 133 percent of the federal poverty level (FPL) and many states exceed this level. No similar protections exist for non-pregnant women. As of July 2004, income eligibility thresholds, mainly parents with dependent children, ranged from 19 percent of FPL in Alabama to 275 percent FPL in Connecticut. Other women were enrolled because they are over age 65 and had below poverty income; this is a national policy that does not vary by state. Many other low income women do not, however, qualify for Medicaid because they do not have children under age 18 , are not over age 65, or are undocumented. In addition, Medicaid managed care arrangements have had an impact on the source of services for women in their childbearing years [24].

Some States have used waiver authority to expand Medicaid coverage to low income, uninsured adults - particularly the parents of children with publicly subsidized coverage. Parents in low-income families may be covered under so-called Section 1931 expansions, which do not require a waiver. More than 40 states and the District of Columbia provide Medicaid coverage to low-income parents through this option. The majority extend short-term coverage to unemployed parents, while other states extend coverage to parents with incomes to 50, 100, or 199 percent FPL, without regard to employment status. Washington State is one state that has used this option to large effect, extending eligibility to 200 percent FPL.

In nearly half of states, special waivers include a focus on adults and may have positive impact on coverage for low-income women of childbearing age. Three types of waivers are of particular importance here: (1) comprehensive waivers broadly designed to cover uninsured adults and make changes to benefits and cost sharing; (2) Health Insurance Flexibility and Accountability (HIFA) waivers, and (3) so-called "family planning" waivers [25]. All three types are authorized under Section 1115 of Medicaid and must be budget neutral. Each type of 1115 requires that states apply for and receive approval by the federal Centers for Medicare and Medicaid Services (CMS).

\section{Comprehensive and HIFA waivers designed to increase health coverage among low-income adults}

Nine states offer Medicaid coverage to low-income parents through Section 1115 waivers. All of these nine states extend coverage to families with incomes at or about 100 percent FPL. Again, some states extend coverage only to unemployed parents, whereas others extend coverage to parents with incomes to 50, 100, or 199 percent FPL, without regard to employment status. Minnesota's waiver extends coverage up to 275 percent FPL [26].

At the beginning of 2006, 11 states had active HIFA waivers, with the primary goal being to encourage new state approaches that increase the number of low-income individuals with health insurance coverage within current-level Medicaid and SCHIP resources [26]. Some of these (e.g., Maine and Michigan) extend coverage only to childless adults. More target the expansions to low-income parents with children enrolled in publicly subsidized coverage (e.g., Arizona, California, Illinois). Still other states sought a waiver for more general expansion of adult coverage.

With enactment of the Deficit Reduction Act of 2005 (DRA), states have increased flexibility to extend coverage, structure alternative benefit packages, and adopt premium and cost sharing requirements without a federal waiver. The DRA creates the potential for states to expand coverage to additional low-income adults, and some states (e.g., Kentucky, West Virginia) are considering expansions to parents of children with Medicaid or other publicly subsidized coverage under the State Children's Health Insurance Program (SCHIP). Such expansions may use limited benefit packages.

\section{Family planning and interconception care waivers}

States have received federal approval for Medicaid waivers programs that offer coverage to low-income women for family planning and reproductive health services. In 2001, nine state programs served 1.7 million women, and recent studies documented cost savings, reductions of unintended pregnancies, and improved use of family planning services in states with these programs [27]. By February 2005, 21 states had created such family planning waivers.

In recent years, 21 states have developed special programs to expand family planning services to women who do not otherwise qualify for Medicaid. Some states offer coverage to women who lose coverage after the birth of a baby or starting a job, while others offer family planning coverage based on income status to men and/or women [28]. 
Of review of 15 state family planning waivers prepared for the National Association of State Medicaid Directors (NASMD) found that core services covered were comprehensive health history and physical examination including appropriate laboratory testing, health education and counseling, approved birth control methods and supplies, and infertility services. Some states provide coverage for services that may be considered preconception care, such as screening for nutrition, folic acid intake, alcohol and tobacco use, genetic conditions, rubella serostatus, domestic violence, and other health risks [29].

An evaluation prepared for CMS of family planning waiver projects in six states found that they resulted in significant savings to both the Federal and State governments, as well as some evidence for expanded geographic availability of services and measurable reductions in unintended pregnancy [30]. This is true, despite the fact that the federal government matches state family planning expenditures at 90/10 for each dollar spent. Greater potential savings and prevention, however, could result if States offered coverage for more comprehensive risk screening, health promotion, and interventions leading toward higher levels of preconception wellness. This would require an extension of states waiver authority aimed at coverage of preconception and interconception care.

\section{Public financing to improve access to primary care}

Preconception care is part of a continuum of women's health services, typically provided in the context of well-woman visits or integral to chronic care management [31-33]. Most components of preconception care can be embedded in the process of primary and preventive care, rather than an isolated visit $[34,35]$. Integration of preconception components into primary care can better serve women across the lifespan and at varying levels of risk [36, 37]. Primary care integrates a variety of health promotion, prevention, and acute care services to address a majority of personal health care needs and common health problems in a community setting [38]. It also may include screening for and ongoing management of chronic conditions in a primary care setting.

National survey data for 2004 indicate that 75 percent of U.S. women ages 18 to 44 had a health care visit in the past year, and most women of reproductive age obtain preventive health services in any given year [17], offering opportunities for clinicians to deliver preconception care. More than half (55 percent) of women had obstetrician/gynecologist visits in the past year. Notably, however, one-third to one-half of women have more than one primary care providers (generally a family physician or internal medicine physician, and an obstetrician/gynecologist) [14]. Some research indicates that having both a reproductive health provider and a primary care provider may increase utilization of clinical preventive services [39].

Having a usual or routine source of care (i.e., a place or provider they usually go when they need health care) is one indicator of health care access and a predictor of certain health behaviors [40]. Women who have a usual source of care are more likely to receive preventive care, to receive continuous care, and to have lower health care costs [14]. As with health coverage, the percentage of women reporting a usual source of care increases with age. Based on detailed survey data from 2002-03, the proportion of women with a usual source of care was 82 percent for ages 18-24, 86 percent for ages 25-34, and 91 percent for ages 35-44 [17]. Proportions also varied by race and ethnicity, with Hispanic women most likely to report no usual source of care. Non-Hispanic Black women were more likely to use a clinic and Non-Hispanic White women more likely to use a physician office as their routine source of care.

These data suggest that publicly subsidized clinics such as community health centers and other federally qualified health centers (FQHCs) might be used to increase access to preconception care among low-income and uninsured women. Community health centers-local, non-profit, community-owned health clinics-serve more than 15 million people in 3,600 low-income, medically underserved, urban and rural communities. Health centers are an important source of primary care for millions of low-income and uninsured women. Nearly 30 percent of all patients are women of childbearing age, and health centers provided prenatal care to over 330,000 women in 2003 [41]. Their patients account for one out of every 10 U.S. births [42]. Research on health centers shows that patients have less infant mortality and low birthweight [43], fewer health disparities [44], improved care for chronic conditions [42], and improved access to primary and preventive care [45]. A study of four states clinics suggests that FQHCs may be an important source of reproductive health services to reduce unintended pregnancies and teen births [46].

Among FQHCs, the Health Disparities Collaboratives Initiative is underway to improve the quality of primary care delivered, and over 600 FQHCs have participated [47]. This quality improvement model is tailored to fit with the staffing and patient patterns of FQHC and is supported by a partnership among community clinics, federal agencies, and national professional organizations. The Health Disparities Collaboratives started with a Chronic Diseases Care Model for quality improvement [48], but now are developing a Primary Health Care model and integrating with the Perinatal Care Collaboratives and other efforts [49].

Health centers receive about one-quarter of their total revenue from direct federal grants. Their single largest source of support is Medicaid, representing more than one-third of total revenues. Patients self-payments, other insurance, and large 
amounts of non-federal grants and contracts make up most of the remainder of health center funding [41]. Thus, federal and state fiscal decisions, in Medicaid and other health program appropriations, affect the fiscal well-being of FQHCs.

\section{Financing public health programs and projects}

Existing public health programs serve millions of women each year. Preconception interventions can be incorporated into these existing programs targeted to reach women at highest risk [50]. Two program examples illustrate the potential, as well as the funding gaps.

The federal Family Planning program is authorized under Title X of the Public Health Service Act. Created in 1970, the Title X program is the only Federal program solely dedicated to family planning and reproductive health with a mandate to provide a broad range of voluntary, affordable, and effective family planning methods and services. The program is particularly designed to provide family planning services to low-income women, many of whom are uninsured and who would have no other source of care. The program provides funds to approximately 4,500 of the estimated 7,000 family planning clinics in the United States and provides reproductive health services to approximately 6.5 million persons each year [27]. Title X-funded clinics provide family planning education, contraceptives, and pregnancy tests; however, many do not offer more comprehensive risk screening and reproductive health promotion and reproductive life planning [51]. If Title $\mathrm{X}$ funding had been increased at the rate of inflation from its FY 1980 funding level, it would have been funded at over $\$ 590$ million in FY $2002[52,53]$. Federal funding was set at only \$288 million for FY 2005 [54]. Without additional funding, it seems unlikely that Title $\mathrm{X}$ clinics will obtain the financial and staff resources to add components of preconception care [55].

Federal and State public health programs funded by the Title V Maternal and Child Health Services Block Grant have the flexibility to give priority to preconception health and offer support for demonstration projects and evaluations of prevention programs. Authorized under Title V of the 1935 Social Security Act, this program provides block grants to states to improve the health of all women, children, youth and families. Title $\mathrm{V}$ funding is an important source of funding for infrastructure building, population-based services, enabling services, and direct health care services. Preconception care is a priority area for some state Title $\mathrm{V}$ programs and is being monitored with performance measures in additional states [51]. Many state Title V agencies have preconception or interconception projects underway or in the design phase, but most of these operate on a small scale or are targeted only to a special population such as teens. Opportunities exist to use Title $\mathrm{V}$ block grant and special project funds more broadly to fund related needs assessment, community-based prevention projects, health education, or preconception care for women. Without additional funding, however, it seems unlikely that new priorities will be adopted and new programs implemented by federal or state Title V-funded entities. As part of an overall funding cut for domestic discretionary programs, Congress reduced FY 2006 funding for the Title V program from $\$ 724$ million to $\$ 700$ million [56].

Although the federally funded Healthy Start projects have interconception health activities, these projects located in communities with high infant mortality have opportunities to offer more systematic pre/interconception screening, health promotion, and interventions. Healthy Start grantees are required to include interconception care activities as part of their overall project. Such activities might include linkage to local providers, tracking postpartum visits, providing case management services, and/or directly provide interconception services [57]. Because Healthy Start funding is linked to Title $\mathrm{V}$ funding overall, resources for more extensive or systematic efforts are limited.

Public health programs funded through the Centers for Disease Control and Prevention (CDC), particularly those offering screening and related services for sexually transmitted diseases and HIV/AIDS also could do more to provide preconception risk assessment and health promotion. Such programs targeted to high risk women are not, however, substitutes for access to primary care and health care coverage.

\section{Conclusions}

Public health policy can be correlated to women's health outcomes [58]. Three major policy and finance directions are proposed by this review paper. To increase access to care among women of childbearing age, the federal and state governments have opportunities to improve health care coverage, increase the supply of publicly subsidized health clinics, and encourage delivery of preconception screening and interventions in the context of public health programs. First and foremost, state and federal policymakers might increase health coverage for low-income women of childbearing age through Medicaid policy changes and waivers. Although health coverage in and of itself may not change health behaviors and health care utilization [59], having access-financial and geographic-to a provider can be seen as threshold requirements for improved health care utilization and delivery of preconception care. A second opportunity is to continue to increase support for community health centers and other federally qualified health centers in medically underserved communities. Last, but not least, policymakers might give greater attention to financing for health promotion and prevention programs, particularly programs such as Title $\mathrm{X}$ and 
Title $\mathrm{V}$ which focus on services to women of childbearing age [60-62].

\section{References}

1. Population Division, US Census Bureau. Table 2: annual estimates of the population by selected age groups and sex for the United States: April 1, 2000 to July 1, 2004 (NC-EST2004-02); 2005.

2. Moos MK, Cefalo RC. Preconceptual health promotion: a focus for obstetric care. Am J Perinatol 1987;47:63-7.

3. Jack BW, Culpepper L. Preconception care: risk reduction and health promotion in preparation for pregnancy. JAMA 1990;264:1147-9.

4. Johnson KA, Posner, SF, Atrash HK, Biermann J, Cordero J, Parker CS, Boulet S, Curtis MG. Recommendations to Improve Preconception Health and Health Care, United States. In press, MMWR Reports and Recommendations; April, 2006.

5. Lu MC, Kotelchuck M, Culhane JF, Hobel CJ, Klerman LV, Thorp JM. The Content of Internatal Care: An approach to preconception care between pregnancies. In press. Matern Child Health J.

6. American College of Obstetricians and Gynecologists, Preconception Work Group. The importance of preconception care in the continuum of women's health care. (ACOG Committee Opinion) OB/GYN. 2005;106(3):665-6.

7. American College of Obstetricians and Gynecologists. Guidelines for women's health care. 2nd ed. Washington, DC: American College of Obstetricians and Gynecologists; 2002.

8. Jack BW, Culpepper L. Preconception care: risk reduction and health promotion in preparation for pregnancy. JAMA 1990;264:1147-9.

9. Jack BW, Culpepper L. Preconception care. J Fam Prac 1991;32:306-15.

10. Korenbrot CC, Steinberg A, Bender C, Newberry S. Preconception care: a systematic review. Matern Child Health J 2002;6:75-88.

11. Atrash, Johnson, Adams, Cordero, Howse. In press, Matern Child Health J.

12. Nathan RP. Federalism and health policy. Health Aff 2005;24(6):1458-66.

13. Personal communication and unpublished data from the National Summit on Preconception Care and the Select Panel on Preconception Care.

14. US Department of Health and Human Services, Health Resources and Services Administration, Maternal and Child Health Bureau. Women's Health USA 2005. Rockville, Maryland: US Department of Health and Human Services; 2005.

15. Kaiser Family Foundation. Medicaid's Role for Women. Issue Brief on Women's Health Policy; November, 2004.

16. Grosse SD, Sotnikkov SV, Leatherman S, Curtis M. The Business Case for Preconception Care: Methods and issues. In press. Matern Child Health J.

17. Salganicoff A, Ranji UR, Wyn R. Women and Health Care: A National Profile - Key findings from the Kaiser Women's Health Survey. Menlo Park, CA: Kaiser Family Foundation; July, 2005. $<$ http://www.kff.org/womenshealth/upload/Women-and-HealthCare-A-National-Profile-Key-Findings-from-the-Kaiser-Womens-Health-Survey.pdf>

18. Kaiser Family Foundation. Women's Health Policy Fact Sheet; November 2004.

19. Holahan J. Washington, DC: Kaiser Commission on the Future of Medicaid; 2003.

20. Kaiser Family Foundation. Factsheet: Medicaid Coverage (\#161304); 2004.
21. Kaiser Family Foundation. Factsheet: Medicaid's Role for Women; 2005.

22. Rosenbaum S. Medicaid's Role in Ambulatory Health Care. J Ambulatory Care Manage 2003;26(4):296-306.

23. www.cms.gov. Accessed; March 2006.

24. Rosenbaum S, Shin P, Mauskopf A, Fund K, Stern G, Zuvekas A. Beyond the freedom to choose. Medicaid, managed care, and family planning. West J Med 1995;163(3S):33-8.

25. Artiga S, Mann C. New Dierctions for Medicaid Section 1115 Waivers: Policy implications of recent waiver activity. Washington, DC: Kaiser Commission on Medicaid and the Uninsured; March, 2005.

26. Centers for Medicare and Medicaid Services. http://www. cms.hhs.gov/HIFA/Accessed; January 2006.

27. Frost JJ, Frohwirth L, Purcell A. The Availability and Use of Publicly Funded Family Planning Clinics: US Trends, 1994-2001. Perspect Sex Reprod Health 2004;36:206-15.

28. Kaiser Family Foundation. Medicaid: A critical source of support for family planning in the United States. Issue Brief on Women's Health Policy; April 2005.

29. National Association of State Medicaid Directors. Review of Medicaid Family Planning Expansion Waivers; 2004. www.nasmd.org.

30. Edwards J, Bronstein J, Adams K. Evaluation of Medicaid Family Planning Demonstrations. The CAN Corporations, CMS Contract No. 752-2-415921; November 2003.

31. Moos MK. Preconceptional health promotion: opportunities abound. Matern Child Health J 2002;6:71-3.

32. Weisman CS. Changing definitions of women's health: Implications for health care and policy. Matern Child Health J 1997;1:17989.

33. Clancy CM, Massion CT. American women's healthcare: A patchwork quilt with gaps. JAMA 1992;268:1918-20.

34. Allaire AD, Cefalo RC. Preconceptional health care model. Eur J Obstet Gynecol Reprod Biol 1998;78:163-8.

35. Frey KA. Preconception care by the non-obstetrical provider. Mayo Clin Proc 2002;77:469-73.

36. Misra DP, Guyer B, Allston A. Integrated perinatal health framework. A multiple determinants model with a life span approach. Am J Prev Med 2003;25:65-75.

37. Lu M, Halfon N. Racial and ethnic disparities in birth outcomes: a life-course perspective. Matern Child Health J 2003;7(1):13-30.

38. Starfield B. Primary Care. New York: Oxford University Press; 1998.

39. Henderson JT, Weisman SC, and Grason H. Are Two Doctors Better than One? Women's Physician Use and Appropriate Care. Women's Health Issues 2002;12(3):138-52.

40. Lambrew J. et al. The Effects of Having a Regular Doctor on Access to Primary Care. Medical Care 1996;34(2):138-51.

41. Proser M. A Nation's Health At Risk II: A front row seat in a changing health care system. Washington, DC: National Association of Community Health Centers; August, 2004.

42. Institute of Medicine. America's Health Care Safety Net: Intact but endangered. Washington, DC: National Academy Press; 2000.

43. Goldman F, Grossman M. The Impact of Public Health Policy: The case of community health centers. East Econ J 1988;14(1):63-72.

44. Politzer RM, Schempf AH, Starfield, et al. Inequality in America: The contribution of health centers in reducing and eliminating disparities in access to care. Med Care Res Rev 2001;58(2):23448.

45. Carlson BL. Primary Care of Patients without Health Insurance by Community Health Centers. J Ambulatory Care Manage 2001;24(2):47-59.

46. Goodman DC, Klerman LV, Johnson KA, Chang C, WrightSlaughter P. Geographic Access to Family Planning Sites and Its Association with Unintended and Teenage Births. Submitted for publication; February 2006. 
47. Healthdisparities.net [homepage on the Internet] Rockville, MD: U.S. Department of Health and Human Services, Health Resources and Services Administration, Bureau of Primary Health Care; [cited 2005 Oct 5] Available from: http://www.health disparities.net/.

48. Bodenheimer T, Wagner EH, Grumbach K. Improving Primary Care for Patients with Chronic Illness. JAMA 2002;288:1775-9.

49. Testimony to the House Energy and Commerce Subcommittee on Oversight and Investigations by HRSA Administrator Elizabeth M. Duke, May 25, 2005. Washington, DC.

50. Boulet SL, Johnson K, Parker C, Posner SF, Atrash H. A National Prescription for Preconception Care. In press, Matern Child Health J.

51. Klerman LV, Johnson KA, Goodman DC, et al. Accessibility of Family Planning Services: Impact of Structural and Organizational Factors. Submitted for publication; February 2006.

52. National Family Planning and Reproductive Health Association. Title X-America's Federal Family Planning Program. Aug. 8, 2003. http://www.nfprha.org/pac/factsheets/titlex.asp Accessed January 2006.

53. Dailard C. The Guttmacher Report on Public Policy; April 2001.

54. Office of Population Affairs, U.S. Department of Health and Human Services. http://opa.osophs.dhhs.gov/titlex/ofp.html Accessed; January 2006.
55. Meier K, McFarlane D. State family planning and abortion expenditures: Their effect on public health. AJPH 1994;84:146872.

56. See Association of Maternal and Child Health Programs. http:// www.amchp.org/legislative/issues_la20.php Accessed January 2006.

57. Maternal and Child Health Bureau, Healthy Start Program, U.S. Department of Health and Human Services. Program Guidance; September 29, 2004.

58. Wisdom JP, Berlin M, Lapidus JA. Relating Health Policy to Women's Health Outcomes. Soc Sci Med Epub 2005;61(8):177684.

59. Case A, Paxson C. Parental Behavior and Child Health. Health Affairs 2002;21(2):164-78.

60. McGinnis JM, Williams-Russo P, Knickman JR. The Case for More Active Policy Attention to Health Promotion. Health Affairs 2002;21(2):7893.

61. Smedley BD, Syme SL, editors. Promoting Health: Intervention strategies from social and behavioral research. Washington, DC: National Academy Press; 2000.

62. Kushner K, Ange E. Women's Health: Successes and Challenges in Prevention and Promotion. Washington, DC: NIHCM Foundation; 2005. 